\title{
Comparative Mutagenic Effectiveness and Efficiency of Physical and Chemical Mutagens in Solanum melongena L. Variety Pusa Uttam
}

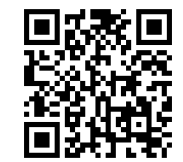

\author{
Danish Shahab ${ }^{* 1,3}$, Mohd Gulfishan ${ }^{2}$, Afaq Ahmad Khan ${ }^{3}$, Csaba Vágvölgyi ${ }^{1}$ and Mohd Yunus Khalil Ansari ${ }^{3}$ \\ ${ }^{1}$ Department of Microbiology, Faculty of Science and Informatics, University of Szeged, Hungary \\ ${ }^{2}$ School of Life and Allied Health Sciences, Glocal University, India \\ ${ }^{3}$ Cytogenetics and Plant Breeding Laboratory, Department of Botany, Aligarh Muslim University, India
}

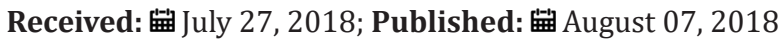

*Corresponding author: Danish Shahab, Guest Researcher, Department of Microbiology Faculty of Science and Informatics University of Szeged, Szeged, Közép fasor 52, H-6726, Hungary

\begin{abstract}
The better understanding of selecting an effective and efficient mutagen may provide better chances to induce high frequency of desirable mutations in any crop breeding program. Present study was carried out with the eggplant (Solanum melongena) variety Pusa Uttam to test the mutagenic effectiveness and efficiency of gamma ray, methyl methane sulphonate (MMS), dimethylsulphate (DMS) and diethyl sulphate (DES) to induce maximum macro-mutations which could eventually be exploited in future as viable and economically important traits. Mutagenic effectiveness and efficiency were calculated as per the standard formulae. In general, the results indicated that mutagenic effectiveness and efficiency decreased with increase in mutagenic treatments. Moreover, the lower or intermediate treatments of gamma rays as well as the alkylating agents were found more effective and efficient in creating maximum mutations with less biological damage. The order of mutagenic effectiveness was MMS > DMS >DES>gamma ray. The order of mutagenic efficiency with regard to inhibition in germination (Mp/I) was same as the effectiveness, while, the orders of efficiency with regard to pollen sterility $(\mathrm{Mp} / \mathrm{S})$ was DMS $>$ DES $>$ MMS $>$ gamma ray. The alkylating agents were found to be more potent than gamma rays in effectively and efficiently widening the genetic base of variability in eggplant and provided greater chances for selecting different desirable characters in future breeding program.
\end{abstract}

Keywords: Solanum Melongena L; Gamma Ray; Alkylating Agents; Mutagenic Effectiveness

\section{Introduction}

Vegetables play a pivotal role in our diet as they are the main source of some important supplements, especially vitamins and minerals. Number of Solanum plants are used as vegetables and from these, eggplant (Solanum melongena) is one of the most common and popular vegetable grown throughout India. Based on production statistics, eggplant is the third most important crop in family Solanaceae, after potato and tomato [1]. Most eggplants in Asia are produced by small-scale farmers, and the sale of the fruits is an important source of cash income [2]. Only China and India account for about $80.6 \%$ of the world's eggplant production area (FAO 2016). The largest eggplant producing countries in the world are China (32 Mt), India (12.5 Mt), Egypt (1.2 Mt) and Turkey (0.9 Mt) [3]. India feeds 17.3 percent of the world's population, which is still growing constantly. Moreover, with 24.5 percent of world's undernourished population, India is bearing a huge burden of global food insecurity (WFP-FSI 2017) [[1]]. Development of new varieties through mutation breeding with higher yield and nutrient content could be particularly beneficial to grower-consumer relationship. It would be especially important in South Asia, where annual per capita vegetable availability ranges from 10 to $54 \mathrm{~kg}$ (FAO 2005), far below the recommended level of $73 \mathrm{~kg}[5,6]$. For any plant breeding program, the availability of genetic variability in the gene pool of a particular crop is of foremost importance because it provides a spectrum of variations for an effective and better selection process. This variability could be increased through recombination, hybridization, and mutations $[7,8]$. Induced mutation provides the possibility of creating desired attributes that either is not present in nature or have been lost during the selection process $[9,10]$. Induced mutagenesis has been established as an important method in many plant improvement programmes by treating seeds and other vegetative plant parts with mutagens [11] and it has immensely contributed to global agriculture by producing over 3248 mutants with desirable qualitative and quantitative traits in different plant species (FAO/IAEA 2017) [12]. The creation of high frequency of desirable mutations depends upon the selection of an effective and efficient mutagen [13]. This study ensures the assessment of the effectiveness and efficiency of gamma ray, MMS, DMS and DES in eggplant's cultivar Pusa Uttam. 


\section{Materials and Methods}

Certified seeds of eggplant (Solanum melongena L.) variety Pusa Uttam (PU) were procured from the Sale Counter of National Seed Centre, Indian Agriculture Research Institute (IARI), New Delhi, India. Dry and healthy seeds (10-12\% moisture content) of variety Pusa Uttam were treated with different doses/ concentrations of gamma ray $(5,10,15,20$ and $15 \mathrm{kR})$, MMS (0.05, $0.075,0.10,0.25$ and $0.50 \%)$, DMS and DES $(0.10,0.25,0.50,0.75$ and $1 \%)$. A set of 150 seeds was used for each dose/concentration including the control. Thereafter, the treated as well as untreated seeds were sown in $30 \mathrm{~cm}$ diameter earthen pots $(50$ seeds in each pot) for raising the seedlings. When the seedlings developed 4 to 5 leaves, were transplanted to wellprepared experimental field in a complete randomized block designs (CRBD) in three replicates for morphological and cytological studies. The row-to-row and plantto-plant distance was maintained at $60 \mathrm{~cm}$ and $45 \mathrm{~cm}$, respectively. Seeds from M1 plants were harvested separately. For raising the M2 generation, $30 \mathrm{M} 1$ plants and 30 seeds from each plant were selected for each treatment, including the control, and seedlings were transplanted in the plant progeny rows ( 3 replicates) at 4 to 5 leaves stage in a complete randomized block design for morphological and cytological studies. Recommended agronomical practices were employed for the preparation of field, sowing and subsequent management of M1 and M2 generation in CRBD [1420].

\section{Frequency of Morphological Mutation}

The morphological mutations were scored on the basis of characters in control plants and their deviations in the treated populations at older stage (75 days old). Following formula was adopted to calculate the frequency of mutation in $\mathrm{M}_{2}$ generation.

$$
\text { Mutation frequency }\left(M_{p}\right)=\frac{\text { No.of mutated plants at older stage }}{\text { Total no.of ger min ated seedlings }} X 100
$$

\section{Mutagenic Effectiveness and Efficiency}

The methods of calculating mutagenic effectiveness and efficiency were suggested [21]. Mutagenic effectiveness is a measure of the frequency of mutation induced by unit dose of a mutagen $(k R$ in case of gamma ray or time $\times$ concentration in case of chemical mutagen), while mutagenic efficiency represents the proportion of mutation in relation to the biological damage.

The formulae suggested by Konzak, were used to evaluate mutagenic effectiveness and efficiency of the mutagens [22].
Mutagenic effectiveness (in case of plysical mutagen $)=\frac{\text { Mutation rate }\left(M_{2} \text { fanily or populationbcois }\right) M_{P}}{\operatorname{DosemKiloRontgen}((K R)}$ Where: $\mathrm{M}_{2}$ )

$M_{p}=$ Percentage of mutated plant progenies (mutation rate in

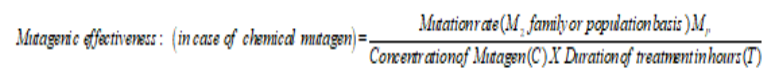

(b) Mutagenic efficiency $=\frac{\text { Percentage of Mutated plant progenies }\left(\text { mutation rate in } M_{2}\right) M_{p}}{{ }^{*} \text { Biolog ical damagein }\left(M_{2}\right) \text { gener ation }}$

*For measuring the biological damage two different criteria were used:

(i) Injury (I): percentage inhibition in seed germination

(ii) Sterility (S): percentage reduction in pollen fertility or percentage pollen sterility

\section{Results}

The effectiveness decreased in all doses of gamma ray from 1.32 to 0.92 in 5 - $25 \mathrm{kR}$ gamma ray, while in DMS there is a sharp decrease from $4.28-2.10$ at $0.1-0.5 \%$ concentration followed by minor decrease in still higher concentrations (Table 1). Similar trend occurred in DES treatments: it decreased sharply from 3.261.12 at $0.1-1 \%$ concentrations (Table 1 ). In MMS the effectiveness increased from 9.8 in $0.05 \%$ MMS to 13.89 and 13.74 at $0.075 \%$ and $0.1 \%$ concentrations, respectively, but in still higher conc. it decreased to 3.15 at $0.50 \%$ conc. (Table 1 ). The most effective dose/concentrations in S. melongena L. var. Pusa Uttam were: $5 \mathrm{kR}$ gamma ray, $0.075 \%$ MMS, $0.10 \%$ DMS and $0.10 \%$ DES. The mutagenic efficiency with regard to inhibition (Mp/I) was higher at low dose of gamma ray (5 kR) and low concentration of MMS (0.05\%) and, thereafter, it decreased at higher doses/ concentrations (Table 1). Whereas in DMS and DES it increased at lower concentrations and decreased at still higher concentrations (Table 1). The most efficient dose/concentrations in S. melongena L. var. Pusa Uttam were: 5 kR gamma ray, 0.05\% MMS, 0.25\% DMS and DES. The mutagenic efficiency based on pollen sterility (Mp/S) was the highest in lower dose/concentrations of gamma ray (5 $\mathrm{kR})$ and DES (0.1\%) and thereafter it decreased in higher doses/ concentrations (Table 1), whereas in MMS and DMS it increased in lower conc. and decreased in still higher concentrations (Table 1). The most efficient dose/concentrations with regard to pollen sterility in S. melongena L. var. Pusa Uttam were: $5 \mathrm{kR}$ gamma ray, 0.075\% MMS, 0.25\% DMS and 0.1\% DES [23-27].

Table 1: Effectiveness and efficiency of gamma ray, $\mathrm{mms}, \mathrm{dms}$ and des treatments in solanum melongena L. Variety pusa uttam $\left(\mathrm{M}_{2}\right.$ generation).

\begin{tabular}{|c|c|c|c|c|c|c|}
\hline Doses/ & $\begin{array}{c}\text { Percentage } \\
\text { of Mutant Plant } \\
\text { Progenies in M2 } \\
\text { (Mp) }\end{array}$ & $\begin{array}{c}\text { \% Inhibition } \\
\text { in Germination } \\
\text { (I) }\end{array}$ & $\begin{array}{c}\text { \% Pollen } \\
\text { Sterility (S) }\end{array}$ & $\begin{array}{c}\text { Mutagenic } \\
\text { Effectiveness Mp/ } \\
\text { CT or kR }\end{array}$ & - & Mutagenic Efficiency \\
\hline Control & - & - & - & & - \\
\hline$\gamma$-Rays & & & & & \\
\hline $5 \mathrm{kR}$ & 6.61 & 3.96 & 1.14 & 1.32 & 1.67 & \\
\hline
\end{tabular}




\begin{tabular}{|c|c|c|c|c|c|c|}
\hline $10 \mathrm{kR}$ & 10.80 & 11.11 & 5.32 & 1.08 & 0.97 & 2.03 \\
\hline $15 \mathrm{kR}$ & 14.71 & 19.05 & 7.50 & 0.98 & 0.77 & 1.96 \\
\hline $20 \mathrm{kR}$ & 18.56 & 23.01 & 13.94 & 0.93 & 0.81 & 1.33 \\
\hline $25 \mathrm{kR}$ & 22.89 & 34.13 & 22.43 & 0.92 & 0.67 & 1.02 \\
\hline \multicolumn{7}{|l|}{ MMS } \\
\hline $0.05 \%$ & 11.76 & 5.56 & 11.74 & 9.80 & 2.12 & 1.00 \\
\hline $0.075 \%$ & 25.00 & 17.46 & 17.18 & 13.89 & 1.43 & 1.46 \\
\hline $0.10 \%$ & 32.97 & 25.39 & 27.87 & 13.74 & 1.30 & 1.18 \\
\hline $0.25 \%$ & 35.29 & 32.53 & 31.01 & 5.88 & 1.08 & 1.14 \\
\hline $0.50 \%$ & 37.80 & 36.51 & 34.40 & 3.15 & 1.04 & 1.10 \\
\hline \multicolumn{7}{|l|}{ DMS } \\
\hline $0.10 \%$ & 10.26 & 7.14 & 4.27 & 4.28 & 1.44 & 2.40 \\
\hline $0.25 \%$ & 22.02 & 13.49 & 8.52 & 3.67 & 1.63 & 2.59 \\
\hline $0.50 \%$ & 25.23 & 16.67 & 18.24 & 2.10 & 1.51 & 1.38 \\
\hline $0.75 \%$ & 29.78 & 25.39 & 24.74 & 1.65 & 1.17 & 1.20 \\
\hline $1.00 \%$ & 33.34 & 35.71 & 32.25 & 1.39 & 0.93 & 1.03 \\
\hline \multicolumn{7}{|l|}{ DES } \\
\hline $0.10 \%$ & 7.82 & 8.73 & 3.21 & 3.26 & 0.90 & 2.44 \\
\hline $0.25 \%$ & 15.45 & 12.70 & 7.57 & 2.58 & 1.22 & 2.04 \\
\hline $0.50 \%$ & 20.00 & 16.67 & 17.17 & 1.67 & 1.20 & 1.16 \\
\hline $0.75 \%$ & 23.95 & 23.81 & 28.24 & 1.33 & 1.01 & 0.85 \\
\hline $1.00 \%$ & 26.82 & 34.92 & 31.22 & 1.12 & 0.77 & 0.86 \\
\hline
\end{tabular}

\section{Discussion}

The usefulness of any mutagen in plant breeding depends not only on its effectiveness but also upon its efficiency to recover high frequency of desirable mutations [28]. In the present experiment, generally the mutagenic effectiveness decreased with increasing doses/concentrations of gamma ray, DMS and DES, but it was higher in lower and intermediate concentrations of MMS. The order of mutagenic effectiveness as determined on the basis of mutated plant progenies in M2 generation was MMS>DMS>DES>gamma ray. Moreover, the alkylating agents were found more effective than gamma ray. The decline in the mutagenic effectiveness at higher doses was due to elimination of severely affected seedlings or plants at an early stage. The toxic effect of the higher doses/conc. of the mutagens on plants may be one of the factors responsible for early elimination of seedlings and eventually resulted in low mutagenic effectiveness. Therefore, it was found to be inversely proportional to the increasing concentrations of mutagens. Similar results as observed with MMS were also noted by Reddi and Suneetha in rice, which provided the evidence that effectiveness did not necessarily increase linearly with increasing concentrations; rather every conc. had its own effectiveness, independent of the other lower and higher concentrations [29]. Mutagenic effectiveness was found to be higher at lower doses/concentrations of physical and chemical mutagens in Vigna unguiculata L. Walp [30], Trigonella foenumgraecum L. [31], Vigna umbellata Thunb, Ohwi and Ohashi [32], Lens culinaris Medik and considered that the chemical mutagens showed higher effectiveness in all above mentioned plants. The mutagenic efficiency indicates the extent of genetic damage recorded in M2 generation in relation to the biological damage caused in the same generation. The order of mutagenic efficiency with regard to inhibition in germination (Mp/I) was MMS>DMS>DES> gamma ray and the order of efficiency with regard to pollen sterility $(\mathrm{Mp} / \mathrm{S})$ was DMS $>$ DES $>$ MMS $>$ Gamma ray. DMS was generally more efficient. Wani (2017) considered that the higher efficiency of a mutagen indicates relatively less biological damage (i.e. seedling injury, sterility) in relation to the mutation induced. Inhibition in seed germination following mutagenic treatments may be due to inhibition of growth regulators and metabolic disturbances during germination. Kumar and Rai have reported that reduction in seed germination is due to the effect of mutagen on meristematic tissues of the embryo of seed and due to the chromosomal damage caused by mutagen. Low chiasma frequency may be one of the causes of low pollen fertility, because chiasmata are responsible for the maintenance of the bivalents which permit normal chromosome segregation and this process ensures pollen fertility [33-36]. The decrease in the chiasma frequency denotes the induced heterology due to induced damage or changed loci of genes or intra/intergenic disturbances following the mutagenic treatments and eventually may cause pollen sterility. The decrease in chiasma frequency may also be attributed to the changes at chromosomal/DNA level, such as deletion, inversion, duplication and translocation. The lower or intermediate treatments were also found to be the most efficient 
in inducing mutations with relatively less biological damage. The higher efficiency obtained at lower or intermediate treatments may be attributed to their less toxic effects on germination of seed and pollen fertility.

In the present study, the alkylating agents were also found more efficient than gamma ray. These results are in agreement with those of earlier researchers like Khan and Tyagi in Glycin max L. Merrill; Wani in Cicer arietinum L.; Tripathy in Lathyrus sativus L.; Mangaiyarkarasi in Catharanthus roseus; Ambli in Pennisetum typhoides. In this context, it is concluded that the alkylating agents were proved to be more effective and efficient than gamma ray to create maximum viable mutations in eggplant variety Pusa Uttam. Out of those mutations, several were screened as desirable mutations of greater economic and agronomic importance in subsequent generation. These mutagens may also be recommended in future mutation breeding programs to obtain desirable mutants in different crops.

\section{Acknowledgement}

The author, Danish Shahab, acknowledges the University Grant Commission (UGC), New Delhi, India for providing UGC Research Fellowship during this study. The gamma ray irradiation facility provided by National Botanical Research Institute (NBRI), Lucknow, India is duly acknowledged.

\section{References}

1. Ali M, Tsou SCS (1997) Combating micronutrient deficiencies through vegetables a neglected food frontier in Asia. Food Policy 22 (1): 17-38.

2. Ambli K, Mullainathan L, Natarajan S (2016) Mutagenic effectiveness and efficiency of gamma rays and ethyl methane sulphonate in pearl millet (Pennisetum typhoides (Burn F) Stapf and CE Hubb) Var CO (cu)-9. Academia Journal Agriculture Research 4(2): 041-044.

3. Ananthaswami HN, Vakil UK, Srinivasan A (1971) Biological and physiological changes in gamma-irradiated wheat during germination. Radiation Botany 11(1): 1-12.

4. Bashir S, Wani AA, Nawchoo IA (2013) Studies on mutagenic effectiveness and efficiency in Fenugreek (Trigonella foenum-graecum L). African Journal of Biotechnology 12(18): 2437-2440.

5. Consolaro MEL, Pagliarinim MS, Chaves LJ (1996) Meiotic behaviour, pollen fertility and seed production in Brazilian populations of Centella asiatica (L) Urban (Umbelliferae). Cytologia 61(4): 375-381.

6. Defani Scoarize MA, Pagliarini MS, Aguiar CG (1995) Case of partial male sterility in an inbred maize line. Cytologia 60(4): 311-318.

7. Dhumal KN, Bolbhat SN (2012) Induction of genetic variability with gamma radiation and its applications in improvement of horse gram. In Adrovic Feriz (Ed) Gamma Radiation., In Tech Publisher Croatia pp. 207-228.

8. FAO (Food and Agriculture Organization of the United Nations) (2005) Agricultural production data collection.

9. FAO (Food and Agriculture Organization of the United Nations) (2011) Agricultural production data collection.

10. FAO (Food and Agriculture Organization of the United Nations) (2016) Agricultural production data collection.

11. FAO/IAEA (2017) Mutant variety database. Vienna, Austria.

12. Girija M, Dhanavel D (2009) Mutagenic effectiveness and efficiency of gamma rays, ethyl methane sulphonate and their combined treatments in cowpea (Vigna unguiculata L Walp). Global Journal Molecular Science $4(2): 68-75$.
13. Gulfishan M, Khan AH, Haneef I, Bhat TA (2011) Genotoxic effect of diethyl sulphate in two varieties of Capsicum annuum L. Nucleus 54: 107-111.

14. Gulfishan M, Khan AH, Jafri IF, Bhat TA (2012) Assessment of mutagenicity induced by MMS and DES in Capsicum annuum L. Saudi Journal of Biological Sciences 19(2): 251-255.

15. Khan AA, Ansari MYK, Bhat TA, Shahab D (2007a) Clastogenic effect of 8-hydroxy Quinoline in Vicia faba L. Advances in Plant Sciences 20(1): 85-87.

16. Khan AA, Ansari MYK, Shahab D, Bhat TA (2007b) Comparative analysis of meiotic abnormalities induced by caffeine and DES in Vicia faba $\mathrm{L}$. Advances in Plant Sciences 20(1): 73-76.

17. Khan MH, Tyagi SD (2010) Studies on effectiveness and efficiency of gamma rays, EMS and their combination in soybean [Glycine max (L) Merrill]. Journal of Plant Breeding and Crop Science 2(3): 055-058.

18. Khan S, Rehman M, Siddiqui BA, Azad SA (1998) Mutagen induced biological damage and chlorophyll mutations in Vigna radiate L. Wilczek. Journal of Indian Botanical Society 77: 143-145.

19. Konzak CF, Nilan RA, Wagner J, Foster RJ (1965) Efficient chemical mutagenesis: The use of induced mutations in plant breeding (FAO / IAEA Meeting, Rome) Radiation Botany 75: 49-70.

20. Kumar G, Rai P (2007) Colchiploidy in soybean (Glycine max) Journal of Cytology and Genetics 8: 17-23.

21. Laskar RA, Khan S (2017) Mutagenic effectiveness and efficiency of gamma rays and $\mathrm{HZ}$ with phenotyping of induced mutations in lentil cultivars. International Letters of National Sciences 64: 17-31.

22. Mangaiyarkarasi RJ, Girija M, Gnanamurthy S (2014) Mutagenic effectiveness and efficiency of gamma rays and ethyl methane sulphonate in Catharanthus roseus. International Journal of Current Microbiology and Applied Sciences 3(5): 881-889.

23. Patial M, Thakur SR, Singh KP (2015) Comparative mutagenic effectiveness and efficiency of physical and chemical mutagen and induced variability in ricebean (Vigna umbellata Thunb, Ohwi and Ohashi). Legume Research 38(1): 30-36.

24. Rashid MA, Alam SN, Rouf FMA, Talekar NS (2003) Socioeconomic parameters of eggplant pest control on Jessore district of Bangladesh. AVRDC he World Vegetable Centre's Technical Bullet p. 29.

25. Reddi TVVS, Suneetha J (1992) Chlorophyll deficient mutations induced in rice by alkylating agents and azide. Cytologia 57(2): 283-288.

26. Roychowdhury R, Tah J (2011) Germination behaviors in $M_{2}$ generation Dianthus after chemical mutagenesis. International Journal of Advances in Science and Technological Research 1(2): 448-454.

27. Rumana A, Bhat TM, Choudhary S, Ansari MYK, Shahwar D (2017) Estimation of genetic variability, mutagenic effectiveness and efficiency in $\mathrm{M}_{2}$ flower mutant lines of Capsicum annuum L. treated with caffeine and their analysis through RAPD markers. Journal of King Saud University Science 29(3): 274-283.

28. Siddique I, Ansari MYK (2005) Studies on the genotoxic effect of pollution on brinjal (Solanum melongena $\mathrm{L}$ ) growing around Harduaganj Thermal Power Plant. Nature Environmental and Pollution Technology 4(1): 13-17.

29. Sideris EG, Nawar MM, Nilan RA (1971) Effect of gamma irradiation on gibberallic acid solution and gibberallic like substances in Barley seedling. Radiation Botany 11: 209-214.

30. Sri Devi A, Mullainathan L (2012) The use of ethyl methanesulfonate to study the flower development in Capsicum annuum L. mutants Botany Research International 5: 4-9.

31. Thilagavathi C, Mullainathan L (2011) Influence of physical and chemical mutagens on quantitative characters of Vigna mungo L (Hepper) International Multidisciplinary Research Journal 1(1): 6-8. 
32. Tripathy SK, Ranjan R, Lenka D (2012) Effectiveness and efficiency of single and combined treatments of physical and chemical mutagens in grasspea (Lathyrus sativus L) World Journal of Agricultural Sciences 8(5): 516-519.

33. Walther $F$ (1969) Effectiveness of mutagen treatments with ionizing radiations in barley. Induced mutations in plants. Proc Sym Nature, Induction and Utilization of Mutations in Plants IAEA / FAO, Pullman, Wash 15-18: 261-270.
34. Wani AA (2011) Spectrum and frequency of macromutations induced in chickpea (Cicer arietinum L). Turkish Journal Biology 35: 221-231.

35. Wani MR (2017) Induced chlorophyll mutations, comparative mutagenic effectiveness and efficiency of chemical mutagens in lentils (Lens culinaris Medik). Asian Journal of Plant Science 16(4): 221-226.

36. (2017) World Food Programme- Food Security in India Quarterly Bulletin.
ISSN: 2574-1241

DOI: 10.26717/BJSTR.2018.07.001541

Danish Shahab. Biomed J Sci \& Tech Res

(C) (P) This work is licensed under Creative

Submission Link: https://biomedres.us/submit-manuscript.php

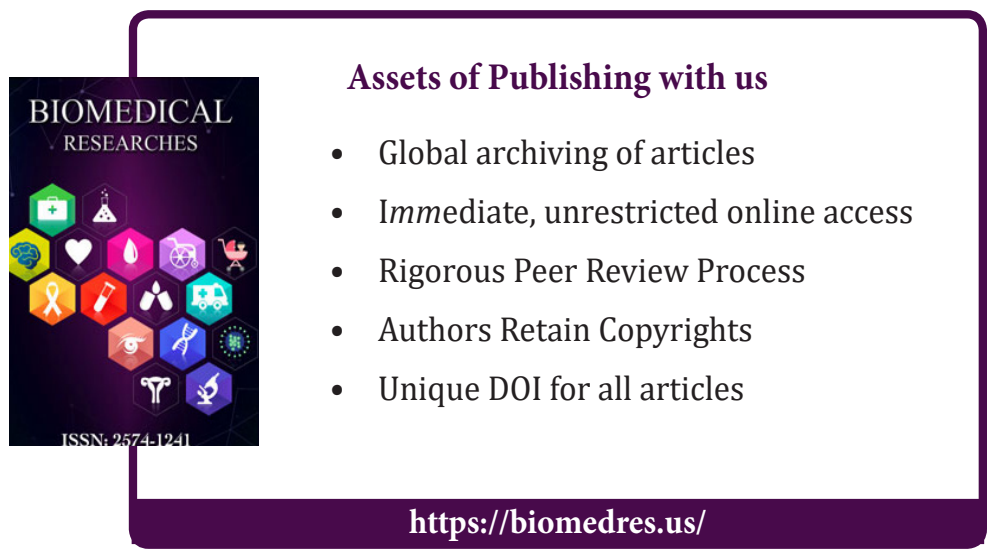

